\title{
Long non-coding RNAs and their functions in plants Julia A Chekanova
}

Eukaryotic genomes encode thousands of long noncoding RNAs (IncRNAs), which play important roles in essential biological processes. Although IncRNAs function in the nuclear and cytoplasmic compartments, most of them occur in the nucleus, often in association with chromatin. Indeed, many IncRNAs have emerged as key regulators of gene expression and genome stability. Emerging evidence also suggests that IncRNAs may contribute to the organization of nuclear domains. This review briefly summarizes the major types of eukaryotic IncRNAs and provides examples of their mechanisms of action, with focus on plant IncRNAs, mainly in Arabidopsis thaliana, and describes current advances in our understanding of the mechanisms of IncRNA action and the roles of IncRNAs in RNA-dependent DNA methylation and in the regulation of flowering time.

\section{Address}

School of Biological Sciences, University of Missouri-Kansas City, Kansas City, MO 64110, USA

Corresponding author: Chekanova, Julia A (chekanovaj@gmail.com)

\section{Current Opinion in Plant Biology 2015, 27:207-216}

This review comes from a themed issue on Cell signalling and gene regulation

Edited by Xiaofeng Cao and Blake C Meyers

http://dx.doi.org/10.1016/j.pbi.2015.08.003

1369-5266/Published by Elsevier Ltd.

\section{Introduction}

Transcriptome studies in fungi, plants, and animals have revealed that pervasive transcription from over $90 \%$ of the genome generates a multitude of non-coding RNAs (ncRNAs) [1,2], including tens of thousands of plant lncRNAs, broadly defined as ncRNAs longer than $200 \mathrm{nt}$ in length that do not have discernable coding potential $\left[3^{\bullet}, 4^{\bullet \bullet}, 5\right]$. Early studies questioned the importance of lncRNAs because of their low expression and sequence conservation compared with mRNAs, and attributed their existence to transcriptional noise. However, emerging evidence indicates that many lncRNAs play key roles in diverse biological processes across eukaryotes, ranging from the regulation of mating type in yeast $[6,7]$ to the pluripotency of embryonic stem cells in mammals [8]. Plant lncRNAs play key roles in flowering time, gene silencing, root organogenesis, seedling photomorphogenesis, and reproduction $\left[5,9^{\bullet}, 10,11^{\bullet}, 12^{\bullet \bullet}, 13^{\bullet \bullet}\right]$.

\section{Types of IncRNAs}

Our emerging understanding of the importance of lncRNAs has only begun to come to terms with their remarkable variety of types and origins. LncRNAs arise from intergenic, intronic, or coding regions in the sense and antisense directions. On the basis of their genomic origins, lncRNAs can be broadly classified as: first, long intergenic ncRNAs (lincRNAs); second, intronic ncRNAs (incRNAs); and third, natural antisense transcripts (NATs) transcribed from the complementary DNA strand of the associated genes (Figure 1a) $\left[14^{\bullet}\right]$.

A comprehensive analysis of over 200 Arabidopsis thaliana transcriptome data sets identified $\sim 40,000$ putative lncRNAs, including over 30,000 NATs and over 6000 lincRNAs $\left[3^{\bullet}, 4^{\bullet \bullet}, 15\right]$. Most of these lncRNAs are not associated with smRNAs and their transcript levels are 30-fold to 60fold lower than those of mRNA, similar to mammalian lncRNAs. NAT pairs, lncRNAs generated from the opposite strands of coding or noncoding genes, are surprisingly widespread in Arabidopsis with $\sim 70 \%$ of Arabidopsis protein-coding loci encoding potential NAT pairs of 20012,370 nt $\left[4^{\bullet \bullet}\right.$. NAT pairs can either overlap completely $(\sim 60 \%)$ or have complementary sequences in their $5^{\prime}$ or $3^{\prime}$ regions (Figure 1a). NAT expression is also highly tissuespecific and many NATs respond to biotic or abiotic stresses. Recent analysis of expression of sense-antisense NAT pairs in response to light uncovered about 1400 light-responsive NATs, with about equal proportions regulated either concordantly or discordantly relative to the sense transcript. Genes encoding many light-responsive NATs also showed high levels of histone acetylation, which dynamically correlated with NAT expression changes $\left[4^{\bullet \bullet}\right]$.

The above classification does not do justice to the rich variety of plant lncRNAs. For example, the diverse group of lincRNAs includes lncRNAs that serve as precursors and/or scaffolds for smRNAs in RNA-dependent DNA methylation (RdDM) silencing pathway (described below), and these lincRNAs likely differ in function from other lincRNAs transcribed by RNA Pol II. Also, ncRNAs produced from PHAS loci serve as precursors to generate 21-nt and 24-nt secondary phased phasiRNAs in many plant genomes [16-18]. Moreover, many additional types of plant lncRNAs likely remain to be discovered.

In addition to lincRNAs, incRNAs, and NATs, work in other organisms has identified various types of lncRNAs transcribed from the regions around transcription start sites (TSSs), enhancer regions, intron splicing sites, and transcription termination sites. The lncRNAs expressed 
Figure 1

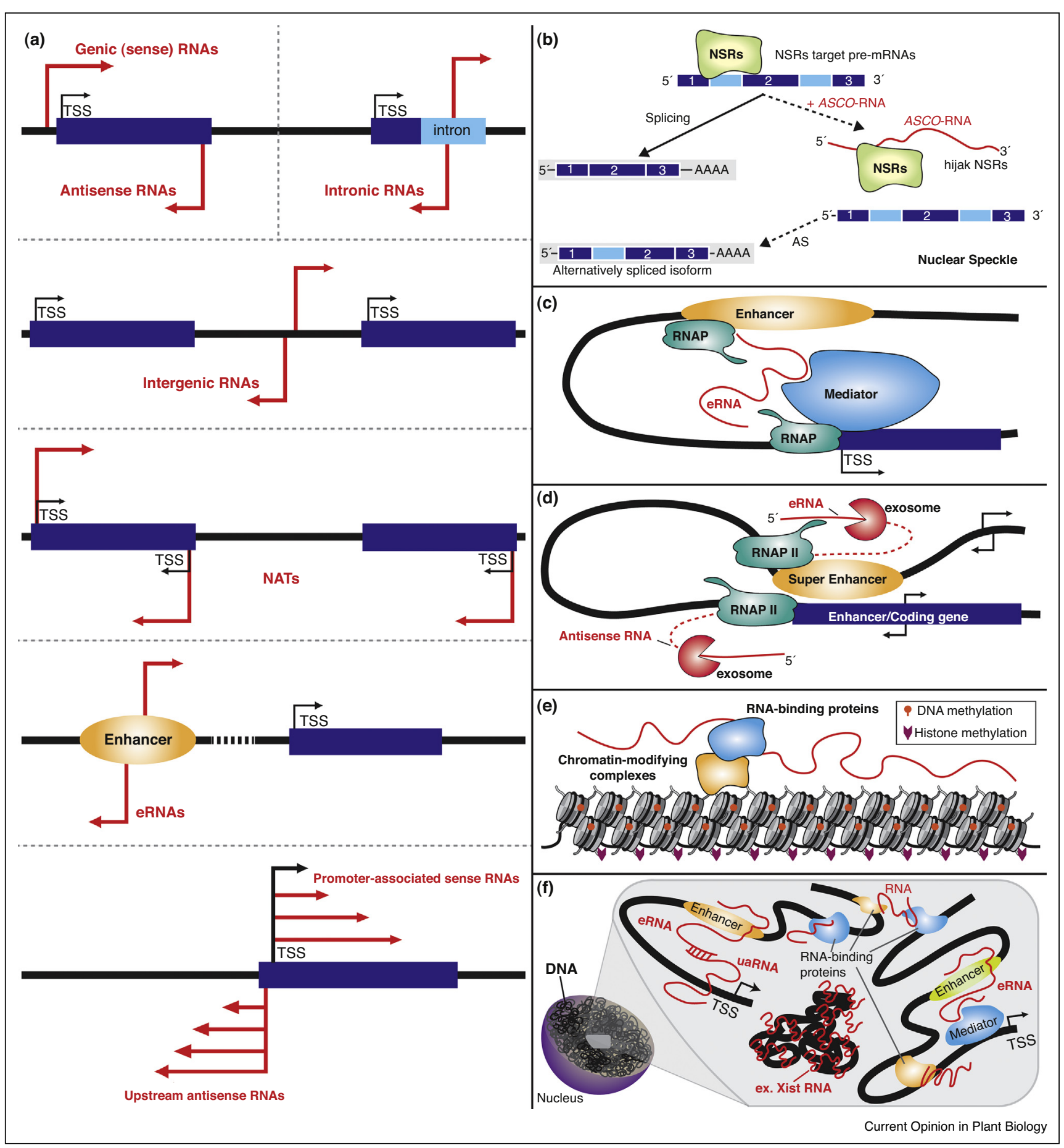

LncRNA types and functions. (a) Classification of IncRNA relative to protein-coding genes. Blue boxes indicate protein-coding genes and red lines indicate IncRNAs. Arrows show the direction of transcription. (b) ASCO-RNA competes with the binding of nuclear speckle RNA-binding proteins (NSRs) to their targets and changes the splicing patterns of NSR-regulated mRNA targets resulting in production of alternative isoforms and alteration of developmental fates in plant roots. (c) eRNAs act as nascent transcripts that function in cis as scaffolds for the recruitment of co-activator complexes mediating chromosome looping between enhancer and promoter regions. (d) The exosome-regulated divergently transcribed seRNAs expressed from super-enhancers can interact with other ncRNAs arising from divergently transcribed enhancer/s or promoter/ $\mathrm{s}$ of protein coding genes, engaging in long-distance interactions and affecting DNA topology and gene expression. (e) LncRNAs serve as scaffolds in the recruitment of chromatin-modifying factors. (f) LncRNAs modulating intra-chromosomal and inter-chromosomal nuclear architecture. Various individual IncRNAs interacting with multiple chromatin proteins and different chromatin domains could act together in establishing and maintaining higher-order structure in the nucleus.(d) Adapted from [36]. 
from around TSSs include exosome-sensitive yeast CUTs (cryptic unstable transcripts) and SUTs (stable unannotated transcripts) [19], mammalian PROMPTs, and uaRNAs (upstream antisense RNAs) [20], Xrn1-sensitive XUTs [21], Nrd1-dependent NUTs [22], and others. A large proportion of mammalian non-polyadenylated lncRNAs also correspond to divergently transcribed, exosome-sensitive eRNAs mapped to enhancer regions [23], although plant eRNAs have not yet been reported.

Recent work in Arabidopsis and rice also uncovered a group of intermediate-sized ncRNAs (im-ncRNAs) of 50$300 \mathrm{nt}$ in length [24,25]. Classification of im-ncRNAs on the basis of their proximity to protein-coding genes identified 299 im-ncRNAs originating from $5^{\prime}$ UTRs, coding, and intronic regions. The presence of $5^{\prime}$ UTR im-ncRNAs correlated with higher expression of the associated genes and with positive histone marks, such as $\mathrm{H} 3 \mathrm{~K} 4 \mathrm{me} 3$ and $\mathrm{H} 3 \mathrm{~K} 9 \mathrm{ac}$, but not with negative marks. Down-regulation of some im-ncRNAs caused molecular or developmental alterations [24].

\section{Expression of IncRNAs}

Most lncRNAs are transcribed by RNA Pol II. Two additional plant-specific RNA polymerases, Pol IV and Pol V, also produce lncRNAs [26,27]. Most lncRNAs are polyadenylated; however, many yeast and mammalian lncRNAs are non-polyadenylated [23]. Some key plant lncRNAs are also non-polyadenylated $[28,29]$ and recent work in Arabidopsis identified hundreds of non-polyadenylated lncRNAs induced by specific abiotic stresses [30].

Many plant lncRNAs are developmentally and environmentally regulated and likely represent functional components of the transcriptome. For example, many lincRNAs show significant changes in different organs or during stress, suggesting that they are dynamically regulated and might function in development and stress responses [15]. However, the regulation of lncRNAs in plants remains poorly understood.

Like all transcripts, lncRNA expression is regulated at the transcriptional level and by the machineries involved in their biogenesis, $3^{\prime}$ end processing and degradation. One of these factors is the exosome complex, the main $3^{\prime}-5^{\prime}$ exoribonuclease machinery conserved in eukaryotes, which comprises a nine-subunit core associated with two additional subunits, Rrp44 and the nuclear-specific Rrp6, which provide the enzymatic activity. Indeed, various groups of polyadenylated ncRNAs were originally identified in Arabidopsis exosome mutants [1]. One of the distinct subclasses of these ncRNAs comprises upstream noncoding transcripts, which we termed UNTs, originating from TSSs of protein-coding genes and resembling CUTs and PROMPTs. UNTs are collinear with the $5^{\prime}$ ends of protein-coding transcripts and frequently extend into the first intron of their respective overlapping genes [1].

\section{Molecular functions of IncRNAs}

LncRNAs can regulate gene expression on multiple levels via a number of complex mechanisms. They can function in either cis or in trans by sequence complementarity or homology with RNAs or DNA, and/or by structure, forming molecular frames and scaffolds for assembly of macromolecular complexes. Most of the studied lncRNAs function in regulation of gene expression at the transcriptional level; however, some lncRNAs have been reported to regulate gene expression posttranscriptionally in a variety of ways.

On the simplest level, lncRNAs can serve as decoys that prevent the access of regulatory proteins to DNA or RNA by mimicking their targets. Some Arabidopsis lncRNAs interact with microRNAs (miRNAs) as competitors and function as miRNA target mimics, similarly to animal miRNA sponges. For example, the IPS1 lncRNA acts as a non-cleavable competitor for $\mathrm{PHO} 2$ mRNA, as miR399 targets the PHO2 mRNA for degradation [31]. Many endogenous miRNA target mimics have also been predicted by bioinformatics approaches and the function of some has been experimentally confirmed in Arabidopsis [32]. The decoy Arabidopsis lncRNA ASCO regulates plant root development by binding to the regulators of alternative splicing, nuclear speckle RNA-binding proteins, and hijacking them to change the patterns of alternative splicing to produce alternative splice isoform (Figure 1b) $\left[12^{\bullet \bullet}\right]$.

The best-known functions of lncRNAs are their roles as regulators of transcription. LncRNAs can directly regulate the Pol II transcription machinery. For example, animal lncRNAs promote the phosphorylation of transcription factors (TFs) and thus regulate their DNAbinding activity [33]. Many eukaryotic lncRNAs play important roles in regulation of transcription initiation and elongation, including control of RNA Pol II pausing, function through transcriptional interference and as scaffolds recruiting chromatin remodelers, which in turn can affect chromatin topology and nuclear organization (reviewed in $\left[34^{\circ}\right]$ ). The Arabidopsis trans-acting lncRNA HID1 associates with the chromatin of the TF gene PIF3 and represses its transcription $\left[13^{\circ}\right]$. The APOLO lincRNA participates in the spatial association and interaction between APOLO and the distant PID genomic regions via formation of a dynamic chromatin loop that determines $P I D$ expression $\left[9^{\circ}\right]$.

Some mammalian enhancer RNAs (eRNAs) act as nascent transcripts and function in cis as scaffolds to recruit co-activator complexes that mediate chromosome looping between enhancer and promoter regions, controlling chromatin topology and modulating gene activation 
(Figure 1c) $\left[35,36^{\circ \bullet}\right]$. eRNAs also function at superenhancers, elements characterized by high densities of individual enhancers. Recent findings suggest that socalled supereRNAs and divergently transcribed lncRNAs produced from other enhancers or TSSs may act together to form higher-order chromosomal structures that enable control of gene expression. Interestingly, in this case the exosome machinery affects enhancer activity by regulating the antisense lncRNAs via either post-transcriptional RNA degradation or by repression of RNA synthesis via promotion of early termination of transcription $\left[36^{\circ \bullet}\right]$. A remarkable correlation was also found between the presence of genes producing exosome regulated TSS-associated antisense lncRNAs in the vicinity of a superenhancer (within up to $310 \mathrm{~kb}$ ), suggesting that expression and/or processing of these lncRNAs may control the interaction between the superenhancers and their counterpart genes. Interestingly, the exosome also protects regions expressing eRNAs from genomic instability by resolving deleterious R-loops [36 $6^{\bullet \bullet}$ ], stable RNA-DNA triplexes that naturally form during transcription, but persist in divergently transcribed regions [37]. These findings led to the proposal that activity of the exosome can modulate the interaction between regulatory elements that control both gene expression and nuclear organization, via regulation of lncRNAs produced from these elements (Figure 1c-f).

Most work on lncRNAs has focused on their roles in the recruitment of chromatin regulatory proteins to genomic DNA locations. Different classes of chromatin-bound lncRNAs function as scaffolds for the cooperative assembly of chromatin-modifying complexes, recruiting them in either smRNA-dependent or smRNA-independent manners. The most-studied RNAi-dependent pathway is plant-specific $\mathrm{RdDM}$, as described below [11 $\left.{ }^{\circ}\right]$. Other lncRNA scaffolds recruit chromatin-modifying complexes independently of smRNAs, although how protein complexes recognize lncRNAs to jointly target genes remains unclear. Mammalian lncRNAs can positively regulate transcription via interacting with Trithorax group proteins to trimethylate histone H3K4 [38], while other lncRNAs negatively regulate transcription via targeting repressive histone-modifying activities, for example by interacting with Polycomb-Repressive Complex 2 (PRC2) to methylate histone H3K27 [39].

Thus, lncRNAs regulate gene expression at the transcriptional and post-transcriptional levels, by multiple, complex mechanisms, which we are just beginning to understand. The sections below provide more detail on two of the best-studied functions of IncRNAs, in RdDM and the regulation of flowering time.

\section{LncRNAs in RdDM}

Plant lncRNAs can contribute to epigenetic silencing via RdDM, which primarily silences repetitive sequences and requires the plant-specific RNA polymerases Pol IV and Pol V [26], with some involvement of RNA Pol II (see Figure 2) [40]. A group of lncRNAs transcribed by Pol IV produces 24-nt small interfering RNAs (siRNAs), and lncRNAs produced by Pol $\mathrm{V}$ function as scaffold RNAs recognized by the siRNA-Ago complex through sequence complementarity (reviewed in $\left[11^{\circ}\right]$ ).

In Arabidopsis, Pol IV generates most siRNAs, although, Pol V and to a lesser extent Pol II produce the templates for siRNAs, indicating the complexity of siRNA biogenesis [41-44]. The lncRNAs produced by Pol IV and Pol V have been difficult to identify, possibly due to their very low abundance or stability. For example, only several Pol V-transcribed scaffold lncRNAs, which are non-polyadenylated and either tri-phosphorylated or capped at the $5^{\prime}$ ends, have been reported to date [26]. Recent work identified Pol IV/RDR2-dependent transcripts, P4RNAs, derived from thousands of loci in Arabidopsis, mainly at intergenic regions, and $65 \%$ of them overlapped with annotated transposons or repeats, but only $9 \%$ of them overlapped with genes $\left[45^{\circ}\right]$. These Pol IV/RDR2-dependent transcripts are non-polyadenylated and, intriguingly, correspond to both DNA strands. A surprising finding was that the $5^{\prime}$ ends of P4RNAs bear a monophosphate instead of a $5^{\prime}$ triphosphate, or a cap structure $\left[45^{\circ}\right]$.

Pol $\mathrm{V}$ transcripts may also have additional functions outside of the RdDM pathway, as indicated by a genome-wide study to identify Pol V-associated loci [46,47]. About $75 \%$ of genomic sites occupied by Pol V correspond to transposons and repeats that are also associated with 24-nt siRNAs and DNA methylation, indicating that Pol $\mathrm{V}$ mediates RdDM at these sites. By contrast, the remaining 25\% of the sites occupied by Pol V lack these features and are biased towards genes, suggesting that Pol V also participates in different silencing pathways [46]. Pol II also produces scaffold transcripts that recruit AGO4bound siRNAs to elicit RdDM and transcriptional gene silencing at some loci [40], suggesting an intricate collaboration between Pol II and Pol V. However, the characteristics that attract Pol II to some intergenic loci and the requirements for Pol II interaction with Pol IV and Pol $\mathrm{V}$ remain unknown.

Our previous genome-wide studies of exosome targets revealed a large number of polyadenylated exosome substrates corresponding to ncRNAs that originate from centromeric regions, repetitive elements and other loci that produce siRNAs and are silenced through RdDM [1]. However, we found that the loss of the Arabidopsis core exosome subunits had a minor effect on global smRNA populations $[1,48]$, by contrast to the fission yeast exosome, which controls the spurious entry of RNAs into smRNA pathways [49]. Instead, it resulted in decreased histone H3K9me2 at several examined RdDM-controlled 
Figure 2

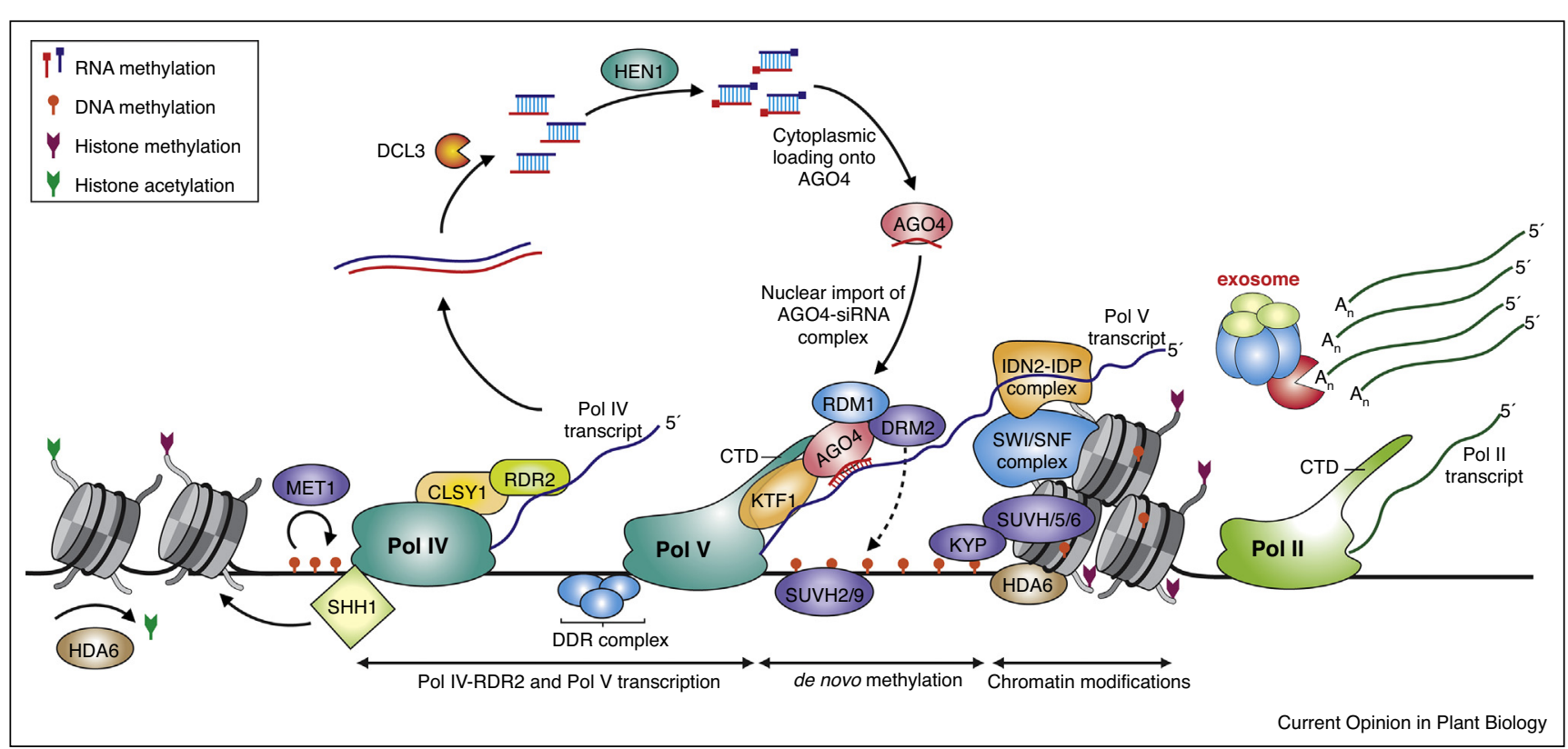

LncRNAs in RdDM. Pol IV transcripts serve as precursors for $24 \mathrm{nt}$ siRNAs and Pol V transcripts act as targets of siRNAs. The H3K9me reader SHH1 recruits Pol IV to its genomic loci and the chromatin remodeler CLSY1 facilitates the passage of Pol IV [74]. Pol IV transcripts are made double-stranded by RDR2, processed by DCL3 into 24-nt siRNAs, stabilized by methylation at the $3^{\prime}$ end, and reimported into the nucleus in the AGO-siRNA complex to guide the targeting of nascent Pol V scaffold transcripts. The DDR complex facilitates Pol V transcription [47]. DNA methylation readers SUVH2 or SUVH9 aid Pol V recruitment to its genomic loci [75] and the IDN2-IDP complex bound to Pol V scaffold RNAs interacts with SWI/SNF complex, which adjusts nucleosome positioning [76]. AGO4 interacts with Pol V and with a putative transcriptional elongation factor KTF1 recruiting AGO4-siRNA to nascent Pol V transcripts. The siRNA base pairs with the nascent Pol V transcript and together with RDM1 (RNA-DIRECTED DNA METHYLATION 1) recruits DRM2 (DOMAINS REARRANGED METHYLTRANSFERASE 2) to catalyze de novo methylation at the homologous genomic sites. H3K9 methylation, deposited by KYP, SUVH5, and SUVH6, amplifies DNA methylation-mediated silencing (reviewed in [11]). Adapted from [11]. In silencing of the solo LTR region, the exosome does not act in siRNA metabolism and DNA methylation. The exosome associates with transcripts emanating from the adjacent scaffold-producing region, and participates in silencing by affecting $\mathrm{H} 3 \mathrm{~K} 9$ histone methylation to maintain or establish chromatin structure, in parallel to RdDM, which affects siRNAs and DNA methylation.

loci. The exosome also exhibits a strong genetic interaction with RNA Pol V, but not Pol IV at these loci, and physically associates with polyadenylated Pol II transcripts arising from the regions generating Pol V scaffold RNAs (Figure 2) [48]. Together, these data suggest that the Arabidopsis exosome participates in the metabolism or processing of lncRNAs produced from scaffold-generating regions and may contribute to coordination of the transcriptional interplay between Pol II, Pol V, and Pol IV RNA polymerases, to achieve the appropriate level of transcriptional repression. How the Arabidopsis exosome or the exosome-controlled lncRNAs facilitate recruitment of chromatin modifiers to enforce silencing through repressive histone modifications remains an open and interesting question.

Arabidopsis exosome complex subunits are functionally diverse [1]. In addition, one of the nuclear catalytic subunits of the exosome complex, RRP6L1, which has exosome core complex-dependent and also complex-independent functions, affects the metabolism of siRNAs and DNA methylation [50] as well, suggesting that exosome subunits functions are essential in regulating various ncRNAs in RdDM, including siRNAs.

\section{LncRNAs in the regulation of flowering}

Epigenetic regulation by lncRNAs plays a key role in the regulation of flowering by controlling the expression of Arabidopsis FLC (FLOWERING LOCUS G). The transcription factor FLC represses flowering in a dosagedependent manner, blocking the expression of genes required for flowering. FLC participates in the vernalization pathway, which regulates flowering time in response to prolonged cold, and in the autonomous pathway, which regulates flowering independently of environmental signals [51]. Epigenetic silencing of $F L C$ plays central roles in both of these pathways and mainly involves histone modifications. PRC2, which methylates histone H3K27, is required for $F L C$ repression and is recruited to the $F L C$ locus before silencing. Epigenetic changes in chromatin structure, particularly the alteration of histone modifications from $\mathrm{H} 3 \mathrm{~K} 4 \mathrm{me} 3$, $\mathrm{H} 3 \mathrm{~K} 36 \mathrm{me} 3$, and $\mathrm{H} 2 \mathrm{Bub} 1$ to $\mathrm{H} 3 \mathrm{~K} 27 \mathrm{me} 3$, alter the epigenetic state at $F L C$ to repress $F L G$ expression (reviewed in [10]). 
Figure 3

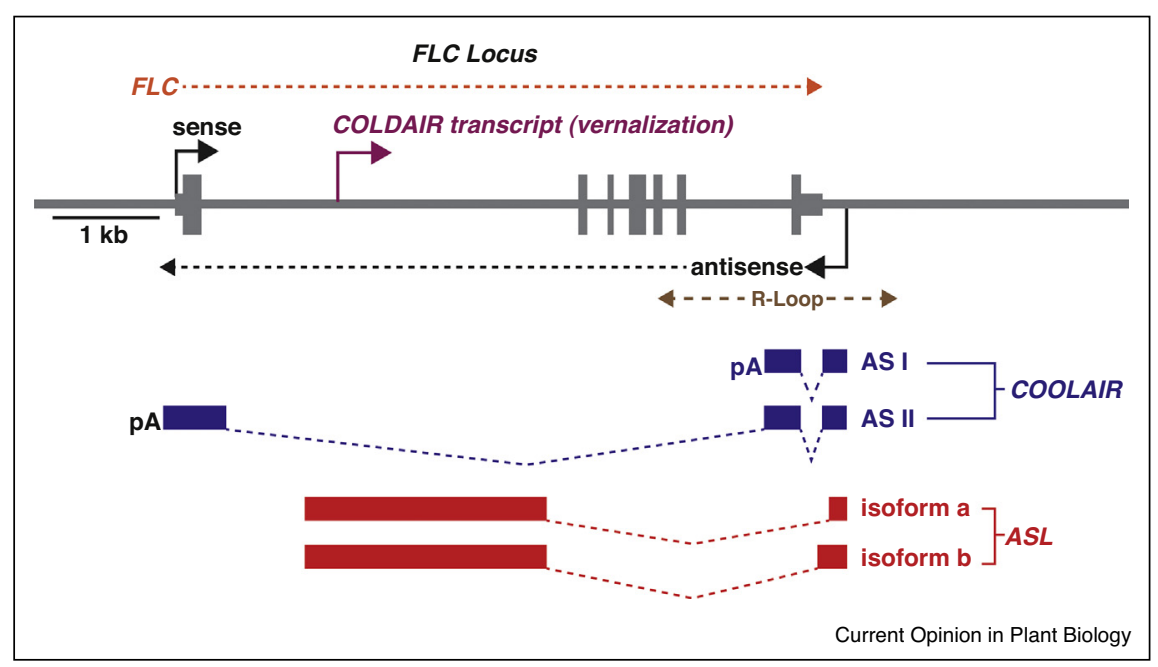

Regulatory IncRNAs produced from the FLC locus. Diagram of the FLC locus [57]. The arrow indicates the FLC transcription start site and vertical bars denote the exons of the FLC sense transcript. COLDAIR IncRNA (purple) is transcribed in vernalization from the first intron of FLC in the sense direction, relative to FLC mRNA. COOLAIR (blue) and ASL (red) are transcribed in the antisense direction; the arrow indicates their transcription start site. COOLAIR AS I and II are alternatively polyadenylated, with a proximal poly(A) site in intron 6 and a distal poly(A) site in the sense promoter region. Blue boxes show AS I and II exons, and blue dotted lines correspond to the spliced regions. ASL is also alternatively spliced: red boxes depict ASL exons and red dotted lines indicate spliced regions. ASL spans the first intron of FLC. Brown dotted lines depict the R loops, which form over the promoter region of COOLAIR. An R-loop that extends from the COOLAIR promoter to the proximal polyadenylation site represses COOLAIR transcription.

Two different classes of lncRNAs transcribed from $F L C$, COLDAIR and COOLAIR, participate in epigenetic silencing of $F L C$ (Figure 3) [28,52]. COLDAIR is a $5^{\prime}$ capped, non-polyadenylated lncRNA transiently induced by vernalization from intron 1 of $F L C$ and transcribed in the same direction as $F L C$ (Figure 3). COLDAIR physically associates with CLF (CURLY LEAF), the plant homolog of the PRC2 enzymatic component EZH2. Knockdown of COLDAIR compromised the cold-mediated enrichment of CLF and H3K27me3 at FLC and impaired FLC repression in response to vernalization, suggesting that vernalization requires COLDAIR [28]. COLDAIR was proposed to be required for $\mathrm{PRC} 2$ recruitment to $F L C$ chromatin to initiate epigenetic silencing, similarly to the models proposed for the mammalian HOTAIR and Xist lncRNAs [39]. However, the fact that mammalian PRC2 binds to unrelated RNAs with high affinity suggests that lncRNAs alone are not sufficient to target PRC2 to initiate silencing $\left[53^{\circ}\right]$.

COOLAIR, a set of several alternatively spliced and polyadenylated IncRNAs (AS I and AS II, proximally and distally polyadenylated, respectively) arises from the $3^{\prime}$ end of $F L C$ in an antisense direction relative to FLC [54]. Cold induces COOLAIR first, before COLDAIR and before the major accumulation of H3K27me3, and COOLAIR was originally proposed to act during the early phase of vernalization [54]. However, disruption of COOLAIR transcription does not disrupt vernalization
[55]. Recent work showed that COOLAIR participates in acceleration of transcriptional shutdown of $F L C$ during vernalization independently of PRC2 and H3K27me3 $[10,56]$. The removal of COOLAIR desynchronized the replacement of $\mathrm{H} 3 \mathrm{~K} 36$ methylation with $\mathrm{H} 3 \mathrm{~K} 27$ me 3 in the intragenic $F L C$ nucleation region, suggesting that COOLAIR or the process of antisense transcription could be required to coordinate the switching of chromatin states [56].

COOLAIR participates in the vernalization and autonomous pathways to repress FLC. In the autonomous pathway the chromatin state of $F L C$ is coupled to processing of COOLAIR [57]. The constituents of the autonomous pathway, FCA, FY, FPA, the cleavage polyadenylation machinery components CstF64 and CstF77, and the spliceosome factor PRP8, promote the choice of proximal polyadenylation site in processing of COOLAIR, favoring the production of AS I [57-59]. This affects the recruitment of the histone demethylase FLD (FLOWERING LOCUS D) to $F L G$ resulting in $\mathrm{H} 3 \mathrm{~K} 4 \mathrm{me} 2$ demethylation of $F L C$ [60].

Recent work also discovered ASL (Antisense Long) transcript in early-flowering Arabidopsis ecotypes that do not require vernalization for flowering [29]. Distinct from other lncRNAs at $F L C$, ASL is a non-polyadenylated, antisense lncRNA $>2000$ nucleotides long, with two alternatively spliced isoforms. ASL is transcribed from 
the same promoter as COOLAIR and their $5^{\prime}$ regions partially overlap. However, ASL spans intron 1, an important region for maintenance of $F L C$ silencing, and it also overlaps with the region that gives rise to COLDAIR in the sense direction. The ASL transcript physically associates with the FLC locus and H3K27me3 [29], suggesting that ASL and COOLAIR play different roles in $F L C$ silencing and perhaps in the maintenance of H3K27me3.

The exosome functions in RNA processing and two exosome components have important functions in lncRNA-mediated regulation of flowering. RRP6, the nuclear-specific catalytic subunit of the exosome complex, has exosome complex-dependent and complex-independent functions [61,62]. Arabidopsis RRP6L1 and RRP6L2 (RRP6-Like) regulate expression or processing of both COOLAIR and ASL; this regulation is independent of the exosome core complex [29]. Although single RRP6L mutants had minor effects on COOLAIR, RRP6L double mutants caused $F L C$ de-repression and delayed flowering. The pattern of down-regulation of AS I and II in RRP6Ls double mutant was somewhat similar to the pattern observed in mutants of $3^{\prime}$-end processing factors CstF64 and CstF77 [29,57], suggesting that RRP6Ls may participate in the 3 '-end processing of COOLAIR.

Surprisingly, RRP6Ls appear to function as the main regulators of ASL synthesis or biogenesis, as their mutants show little or no ASL transcript. This observation is intriguing since RRP6 is a $3^{\prime}-5^{\prime}$ exoribonuclease and RRP6 defects usually result in over-accumulation of various RNAs due to failures of RNA degradation or processing. However, recent work reported that a surprisingly high number of yeast mRNAs also showed decreased abundance in $\operatorname{rrp} 6 \Delta$ mutants $\left[63^{\circ}{ }^{\circ}\right]$. Similarly, in humans, inactivation of the RRP6 homolog dramatically reduces the levels of Xist, which functions in Xchromosome inactivation [64].

RRP6Ls also affect epigenetic modification of $F L C$; for example, RRP6L mutants exhibit decreased levels of H3K27me3 and lowered nucleosome density at the $F L C$ locus, correlated with FLC de-repression and flowering delay in these mutants. RRP6L1 physically associated with the ASL transcript and directly interacted with the $F L C$ locus, suggesting that RRP6L proteins may participate in the maintenance of $\mathrm{H} 3 \mathrm{~K} 27 \mathrm{me} 3$ via regulation of ASL. Thus, RRP6Ls participate in the regulation of synthesis or biogenesis of FLC lncRNAs and might also act in different $F L C$ silencing pathways by regulating diverse antisense transcripts [29].

COOLAIR transcription is affected by R-loops, which form over the COOLAIR promoter region, and a mutant of TF AtNDX showed de-stabilized R-loops and increased COOLAIR transcription [65]. However, the increase in
COOLAIR transcription in this mutant was also accompanied by increased FLC expression and delayed flowering; thus, the role of R-loop formation over the COOLAIR promoter in the regulation of $F L C$ remains unclear. The formation of R-looped structures can arise from failure of transcriptional termination [66], which itself serves as a mechanism for co-transcriptional exosome recruitment through the noncanonical $3^{\prime}$ end-processing pathway [63 $3^{\circ}$ ]. RRP6 also participates in resolving deleterious R-loops in mammalian cells $\left[36^{\circ}\right]$, suggesting that plant RRP6Ls may act similarly in the processing of FLC antisense transcripts and participate in resolving R-loops. These observations suggest that the lncRNA-mediated regulation of $F L C$ is even more complex than previously thought.

Many mammalian lncRNAs play crucial roles in bringing together proteins, RNA, and DNA to actively shape three-dimensional nuclear organization (Figure 1f) $\left[67^{\bullet \bullet}, 68,69\right]$. Although information about the role of lncRNAs in nuclear architecture in plants is only beginning to emerge, several studies hint that this mechanism might also act in plants. First, the RdDM pathway may contribute to higher-order chromatin structure through collaborating with the MORC proteins. Arabidopsis MORC6 has been proposed to provide ATPase activity for DMS3, a component of DDR complex, to form a functional analogue of a cohesin-like protein required for $\mathrm{X}$-chromosome inactivation in mice. In accord, mutant plants deficient in MORC1 and MORC6 show decondensation of pericentromeric heterochromatin [70]. Second, the $F L C$ promoter and $3^{\prime}$ terminator regions form a short-distance interactions known as gene loops [71,72]. Similar chromatin loops formed between the locus that gives rise to the APOLO lincRNA and the distant genomic regions of the PID gene, and APOLO lincRNA affects the spatial association of these loci. The dynamics of the APOLO region loop formation is controlled via RdDM, active DNA demethylation, and Polycomb complexes $\left[9^{\circ}\right] . F L G$ alleles also physically cluster during epigenetic silencing in vernalization, forming long-distance interactions, and this process is dependent on the PRC2 trans-acting factors VRN5 and VERNALIZATION 2 [73]. However, the role of IncRNAs in this process remains unclear.

The example of $F L G$ illustrates the diverse, complex, and essential roles that lncRNAs play in plants. Moreover, although many studies have improved our understanding of the functions of lncRNAs, emerging work has only begun to reveal the mechanisms that regulate lncRNAs, illustrating the key importance of transcription and RNAprocessing activities in this regulation.

\section{Conclusions and outlook}

In the short time since the discovery of pervasive transcription, studies in plants, animals, and fungi have significantly 
expanded our knowledge of lncRNA biology, particularly in identification of different categories of lncRNAs. By contrast, much remains to be understood about lncRNA functions and mechanisms of action, particularly in plants. Remarkable progress has been made in elucidating the roles of plant lncRNAs in regulation of flowering time and in RdDM. However, the roles of very few other plant lncRNAs have been explored to date. Details on the regulation of synthesis and biogenesis of lncRNAs in plants also remain scant. Ongoing and future work to balance our understanding by identifying factors controlling the expression and biogenesis of IncRNAs and integrating this knowledge with the information learned about the components functioning with these lncRNAs will provide crucial insights into the mechanisms of lncRNA function. Moreover, addressing all angles of the problem will also enable synergistic advances that will allow plant lncRNAs to be better understood. Many discoveries are waiting to be unearthed for myriad plant lncRNAs.

\section{Acknowledgments}

I apologize to all colleagues whose work could not be cited due to the size limitations of this manuscript. I thank Hsiao-Lin Wang for critical reading of the manuscript and help with figures.

This work was supported in part by grants from the NSF (Award\# 0724168), the USDA (Award \# 2007-35301-18207) and the NIH (RO1GM073872) to JAC.

\section{References and recommended reading}

Papers of particular interest, published within the period of review, have been highlighted as:

- of special interest

$\bullet$ of outstanding interest

1. Chekanova JA, Gregory BD, Reverdatto SV, Chen H, Kumar R, Hooker T, Yazaki J, Li P, Skiba N, Peng Q, Alonso J, Brukhin V, Grossniklaus U, Ecker JR, Belostotsky DA: Genome-wide highresolution mapping of exosome substrates reveals hidden features in the Arabidopsis transcriptome. Cell 2007, 131:13401353 http://dx.doi.org/10.1016/j.cell.2007.10.056.

2. Kapranov $P$, Cheng J, Dike S, Nix DA, Duttagupta R, Willingham AT, Stadler PF, Hertel J, Hackermüller J, Hofacker IL, Bell I, Cheung E, Drenkow J, Dumais E, Patel S, Helt G, Ganesh M, Ghosh S, Piccolboni A, Sementchenko V, Tammana H, Gingeras TR: RNA maps reveal new RNA classes and a possible function for pervasive transcription. Science 2007, 316:1484-1488 http://dx.doi.org/10.1126/science.1138341.

3. Jin J, Liu J, Wang H, Wong L, Chua NH: PLncDB: plant long non- coding RNA database. Bioinformatics 2013, 29:1068-1071 http:// dx.doi.org/10.1093/bioinformatics/btt107.

The authors describe the development of an online plant long non-coding RNA database (PLncDB), which provides comprehensive information about plant IncRNAs.

4. Wang H, Chung PJ, Liu J, Jang IC, Kean MJ, Xu J, Chua NH:

-. Genome-wide identification of long noncoding natural antisense transcripts and their responses to light in Arabidopsis. Genome Res 2014, 24:444-453 http://dx.doi.org/ 10.1101/gr.165555.113.

This comprehensive study provides information on genome-wide identification of Arabidopsis NATs.

5. Zhang Y-C, Liao J-Y, Li Z-Y, Yu Y, Zhang J-P, Li Q-F, Qu L-H, Shu W-S, Chen Y-Q: Genome-wide screening and functional analysis identify a large number of long noncoding RNAs involved in the sexual reproduction of rice. Genome Biol 2014, 15:512 http://dx.doi.org/10.1186/s13059-014-0512-1.
6. van Werven FJ, Neuert G, Hendrick N, Lardenois A, Buratowski S, van Oudenaarden A, Primig M, Amon A: Transcription of two long noncoding RNAs mediates mating-type control of gametogenesis in budding yeast. Cell 2012, 150:1170-1181 http://dx.doi.org/10.1016/j.cell.2012.06.049.

7. Zofall M, Yamanaka S, Reyes-Turcu FE, Zhang K, Rubin C, Grewal SIS: RNA elimination machinery targeting meiotic mRNAs promotes facultative heterochromatin formation. Science 2012, 335:96-100 http://dx.doi.org/10.1126/ science.1211651.

8. Flynn RA, Chang HY: Long noncoding RNAs in cell-fate programming and reprogramming. Cell Stem Cell 2014, 14:752761 http://dx.doi.org/10.1016/j.stem.2014.05.014.

9. Ariel $F$, Jégu T, Latrasse $D$, Romero-Barrios $N$, Christ $A$,

- $\quad$ Benhamed M, Crespi M: Noncoding transcription by alternative RNA polymerases dynamically regulates an auxin-driven chromatin loop. Mol Cell 2014, 55:383-396 http://dx.doi.org/ 10.1016/j.molcel.2014.06.011.

This study demonstrates that transcription of Arabidopsis APOLO IncRNA can participate in the spatial association between the distant genomic regions via formation of a dynamic chromatin loop and affect the expression of these regions.

10. Berry S, Dean C: Environmental perception and epigenetic memory: mechanistic insight through FLC. Plant J 2015, 83:133-148 http://dx.doi.org/10.1111/tpj.12869.

11. Matzke MA, Mosher RA: RNA-directed DNA methylation: an

- epigenetic pathway of increasing complexity. Nat Rev Genet 2014, 15:394-408 http://dx.doi.org/10.1038/nrg3683.

In-depth review of our current understanding of RdDM pathways.

12. Bardou F, Ariel F, Simpson CG, Romero-Barrios N, Laporte P

- Balzergue S, Brown JWS, Crespi M: Long noncoding RNA modulates alternative splicing regulators in Arabidopsis. Dev Cell 2014, 30:166-176 http://dx.doi.org/10.1016/ j.devcel.2014.06.017.

This study demonstrates that IncRNAs can modulate expression of alternative splicing regulators in plants. The decoy IncRNA ASCO competes against mRNAs for binding to NSR splicing regulators.

13. Wang $Y$, Fan X, Lin F, He G, Terzaghi W, Zhu D, Deng XW:

- Arabidopsis noncoding RNA mediates control of photomorphogenesis by red light. Proc Natl Acad Sci U S A 2014, 111:10359-10364 http://dx.doi.org/10.1073/ pnas.1409457111.

The Arabidopsis IncRNA HID1 acts in trans and as a component of RNAprotein complex associates with the chromatin of the transcription factor PIF3 to represses its transcription. HID1 IncRNA structure is essential for its function in regulation of photomorphogenesis.

14. Mattick JS, Rinn JL: Discovery and annotation of long

- noncoding RNAs. Nat Struct Mol Biol 2015, 22:5-7 http:// dx.doi.org/10.1038/nsmb.2942.

This review discusses general considerations, principles, and best practices in definition and annotation of eukaryotic IncRNAs.

15. Liu J, Jung C, Xu J, Wang H, Deng S, Bernad L, Arenas-Huertero C, Chua $\mathrm{NH}$ : Genome-wide analysis uncovers regulation of long intergenic noncoding RNAs in Arabidopsis. Plant Cell 2012, 24:4333-4345 http://dx.doi.org/10.1105/tpc.112.102855.

16. Zhai J, Zhang H, Arikit S, Huang K, Nan G-L, Walbot V, Meyers BC: Spatiotemporally dynamic, cell-type-dependent premeiotic and meiotic phasiRNAs in maize anthers. Proc Natl Acad Sci U $S$ A 2015, 112:3146-3151 http://dx.doi.org/10.1073/ pnas.1418918112.

17. Fei Q, Xia R, Meyers BC: Phased, secondary, small interfering RNAs in posttranscriptional regulatory networks. Plant Cell 2013, 25:2400-2415 http://dx.doi.org/10.1105/tpc.113.114652.

18. Zheng $Y$, Wang $Y$, Wu J, Ding B, Fei Z: A dynamic evolutionary and functional landscape of plant phased small interfering RNAs. BMC Biol 2015, 13:32 http://dx.doi.org/10.1186/s12915015-0142-4.

19. Xu Z, Wei W, Gagneur J, Perocchi F, Clauder-Münster S, Camblong J, Guffanti E, Stutz F, Huber W, Steinmetz LM: Bidirectional promoters generate pervasive transcription in yeast. Nature 2009, 457:1033-1037 http://dx.doi.org/10.1038/ nature 07728. 
20. Flynn RA, Almada AE, Zamudio JR, Sharp PA: Antisense RNA polymerase II divergent transcripts are $\mathrm{P}$-TEFb dependent and substrates for the RNA exosome. Proc Natl Acad SciU S A 2011, 108:10460-10465 http://dx.doi.org/10.1073/pnas.1106630108.

21. van Dijk EL, Chen CL, d'Aubenton-Carafa $Y$, Gourvennec $S$, Kwapisz M, Roche V, Bertrand C, Silvain M, Legoix-Né P, Loeillet S, Nicolas A, Thermes C, Morillon A: XUTs are a class of Xrn1-sensitive antisense regulatory non-coding RNA in yeast. Nature 2011, 475:114-117 http://dx.doi.org/10.1038/nature10118.

22. Schulz D, Schwalb B, Kiesel A, Baejen C, Torkler P, Gagneur J, Soeding J, Cramer P: Transcriptome surveillance by selective termination of noncoding RNA synthesis. Cell 2013, 155:10751087 http://dx.doi.org/10.1016/j.cell.2013.10.024.

23. Andersson R, Gebhard C, Miguel-Escalada I, Hoof I, Bornholdt J, Boyd M, Chen Y, Zhao X, Schmidl C, Suzuki T, Ntini E, Arner E, Valen E, Li K, Schwarzfischer L, Glatz D, Raithel J, Lilje B, Rapin N, Bagger FO, Jørgensen M, Andersen PR, Bertin N, Rackham O, Burroughs AM, Baillie JK, Ishizu Y, Shimizu Y, Furuhata E, Maeda S, Negishi Y, Mungall CJ, Meehan TF, Lassmann T, Itoh M, Kawaji H, Kondo N, Kawai J, Lennartsson A, Daub CO, Heutink P, Hume DA, Jensen TH, Suzuki H, Hayashizaki Y, Müller F, Consortium TF, Forrest ARR, Carninci P, Rehli M, Sandelin A: An atlas of active enhancers across human cell types and tissues. Nature 2014, 507:455-461 http://dx.doi.org/10.1038/nature12787.

24. Wang $Y$, Wang X, Deng W, Fan X, Liu T-T, He G, Chen R, Terzaghi W, Zhu D, Deng XW: Genomic features and regulatory roles of intermediate-sized non-coding RNAs in Arabidopsis. Mol Plant 2014, 7:514-527 http://dx.doi.org/10.1093/mp/sst177.

25. Liu T-T, Zhu D, Chen W, Deng W, He H, He G, Bai B, Qi Y, Chen R, Deng XW: A global identification and analysis of small nucleolar RNAs and possible intermediate-sized non-coding RNAs in Oryza sativa. Mol Plant 2013, 6:830-846 http:// dx.doi.org $/ 10.1093 / \mathrm{mp} / \mathrm{sss} 087$.

26. Wierzbicki AT, Haag JR, Pikaard CS: Noncoding transcription by RNA polymerase Pol IVb/Pol V mediates transcriptional silencing of overlapping and adjacent genes. Cell 2008 135:635-648 http://dx.doi.org/10.1016/j.cell.2008.09.035.

27. Li L, Eichten SR, Shimizu R, Petsch K, Yeh C-T, Wu W, Chettoor AM, Givan SA, Cole RA, Fowler JE, Evans MMS Scanlon MJ, Yu J, Schnable PS, Timmermans MCP, Springer NM, Muehlbauer GJ: Genome-wide discovery and characterization of maize long non-coding RNAs. Genome Biol 2014, 15:R40 http://dx.doi.org/10.1186/ gb-2014-15-2-r40.

28. Heo JB, Sung S: Vernalization-mediated epigenetic silencing by a long intronic noncoding RNA. Science 2011, 331:76-79 http://dx.doi.org/10.1126/science.1197349.

29. Shin J-H, Chekanova JA: Arabidopsis RRP6L1 and RRP6L2 function in FLOWERING LOCUS C silencing via regulation of antisense RNA synthesis. PLoS Genet 2014, 10:e1004612 http:// dx.doi.org/10.1371/journal.pgen.1004612.

30. Di C, Yuan J, Wu Y, Li J, Lin H, Hu L, Zhang T, Qi Y, Gerstein MB, Guo $Y$, Lu ZJ: Characterization of stress-responsive IncRNAs in Arabidopsis thaliana by integrating expression, epigenetic and structural features. Plant $J$ 2014, 80:848-861 http:// dx.doi.org/10.1111/tpj.12679.

31. Franco-Zorrilla JM, Valli A, Todesco M, Mateos I, Puga MI, RubioSomoza I, Leyva A, Weigel D, García JA, Paz-Ares J: Target mimicry provides a new mechanism for regulation of microRNA activity. Nat Genet 2007, 39:1033-1037 http:// dx.doi.org/10.1038/ng2079.

32. Wu HJ, Wang ZM, Wang M, Wang XJ: Widespread long noncoding RNAs as endogenous target mimics for microRNAs in plants. Plant Physiol 2013, 161:1875-1884 http:// dx.doi.org/10.1104/pp.113.215962.

33. Wang $P$, Xue $Y$, Han $Y$, Lin L, Wu C, Xu S, Jiang Z, Xu J, Liu Q, Cao $X$ : The STAT3-binding long noncoding RNA Lnc-DC controls human dendritic cell differentiation. Science 2014, 344:310-313 http://dx.doi.org/10.1126/science.1251456.

34. Bonasio R, Shiekhattar R: Regulation of transcription by long

- noncoding RNAs. Annu Rev Genet 2014, 48:433-455 http:// dx.doi.org/10.1146/annurev-genet-120213-092323.
A comprehensive review of the role of IncRNAs in regulation of transcription in eukaryotes.

35. Lai F, Orom UA, Cesaroni M, Beringer M, Taatjes DJ, Blobel GA Shiekhattar R: Activating RNAs associate with mediator to enhance chromatin architecture and transcription. Nature 2013, 494:497-501 http://dx.doi.org/10.1038/nature11884.

36. Pefanis E, Wang J, Rothschild G, Lim J, Kazadi D, Sun J,

- Federation A, Chao J, Elliott O, Liu Z-P, Economides AN, Bradner JE, Rabadan R, Basu U: RNA exosome-regulated long non-coding RNA transcription controls super-enhancer activity. Cell 2015, 161:774-789 http://dx.doi.org/10.1016/ j.cell.2015.04.034.

This study demonstrates the role of the exosome complex in regulation of human superenhancer activity.

37. Skourti-Stathaki K, Proudfoot NJ: A double-edged sword: $\mathbf{R}$ loops as threats to genome integrity and powerful regulators of gene expression. Genes Dev 2014, 28:1384-1396 http:// dx.doi.org/10.1101/gad.242990.114.

38. Wang KC, Yang YW, Liu B, Sanyal A, Corces-Zimmerman R, Chen Y, Lajoie BR, Protacio A, Flynn RA, Gupta RA, Wysocka J, Lei M, Dekker J, Helms JA, Chang HY: A long noncoding RNA maintains active chromatin to coordinate homeotic gene expression. Nature 2011, 472:120-124 http://dx.doi.org/10.1038/ nature09819.

39. Tsai MC, Manor O, Wan Y, Mosammaparast N, Wang JK, Lan F, Shi Y, Segal E, Chang HY: Long noncoding RNA as modular scaffold of histone modification complexes. Science 2010, 329:689-693 http://dx.doi.org/10.1126/science.1192002.

40. Zheng B, Wang Z, Li S, Yu B, Liu JY, Chen X: Intergenic transcription by RNA polymerase II c transcriptional gene silencing in Arabidopsis. Genes Dev 2009, 23:2850-2860 http:// dx.doi.org/10.1101/gad.1868009.

41. Zhang X Henderson IR, Lu C, Green PJ, Jacobsen SE: Role of RNA polymerase IV in plant small RNA metabolism. Proc Natl Acad Sci U S A 2007, 104:4536-4541 http://dx.doi.org/10.1073/ pnas.0611456104.

42. Lee T-F, Gurazada SGR, Zhai J, Li S, Simon SA, Matzke MA, Chen X, Meyers BC: RNA polymerase V-dependent small RNAs in Arabidopsis originate from small, intergenic loci including most SINE repeats. Epigenetics 2012, 7:781-795 http:// dx.doi.org/10.4161/epi.20290.

43. You W, Lorkovic ZJ, Matzke AJM, Matzke M: Interplay among RNA polymerases II, IV and V in RNA-directed DNA methylation at a low copy transgene locus in Arabidopsis thaliana. Plant Mol Biol 2013, 82:85-96 http://dx.doi.org/10.1007/ s11103-013-0041-4.

44. Sasaki T, Lee T-F, Liao W-W, Naumann U, Liao J-L, Eun C, Huang Y-Y, Fu JL, Chen P-Y, Meyers BC, Matzke AJM, Matzke M: Distinct and concurrent pathways of Pol II- and Pol IVdependent siRNA biogenesis at a repetitive trans-silencer locus in Arabidopsis thaliana. Plant J 2014, 79:127-138 http:// dx.doi.org/10.1111/tpj.12545.

45. Li S, Vandivier LE, Tu B, Gao L, Won SY, Li S, Zheng B,

- Gregory BD, Chen X: Detection of Pol IV/RDR2-dependent transcripts at the genomic scale in Arabidopsis reveals features and regulation of siRNA biogenesis. Genome Res 2015, 25:235-245 http://dx.doi.org/10.1101/gr.182238.114.

This pioneering study reported the discovery of RNA Pol IV transcripts and described their features.

46. Wierzbicki AT, Cocklin R, Mayampurath A, Lister R, Rowley MJ, Gregory BD, Ecker JR, Tang H, Pikaard CS: Spatial and functional relationships among Pol V-associated loci, Pol IVdependent siRNAs, and cytosine methylation in the Arabidopsis epigenome. Genes Dev 2012, 26:1825-1836 http:// dx.doi.org/10.1101/gad.197772.112.

47. Zhong X, Hale CJ, Law JA, Johnson LM, Feng S, Tu A, Jacobsen SE: DDR complex facilitates global association of RNA polymerase $\mathbf{V}$ to promoters and evolutionarily young transposons. Nat Struct Mol Biol 2012, 19:870-875 http:// dx.doi.org/10.1038/nsmb.2354

48. Shin J-H, Wang H-LV, Lee J, Dinwiddie BL, Belostotsky DA Chekanova JA: The role of the Arabidopsis exosome in 
siRNA-independent silencing of heterochromatic loci. PLOS Genet 2013, 9:e1003411 http://dx.doi.org/10.1371/ journal.pgen.1003411.

49. Bühler M, Spies N, Bartel DP, Moazed D: TRAMP-mediated RNA surveillance prevents spurious entry of RNAs into the Schizosaccharomyces pombe siRNA pathway. Nat Struct Mol Biol 2008, 15:1015-1023 http://dx.doi.org/10.1038/nsmb.1481.

50. Zhang H, Tang K, Qian W, Duan C-G, Wang B, Zhang H, Wang $P$, Zhu X, Lang Z, Yang Y, Zhu J-K: An Rrp6-like protein positively regulates noncoding RNA levels and DNA methylation in Arabidopsis. Mol Cell 2014, 54:418-430 http://dx.doi.org/ 10.1016/j.molcel.2014.03.019.

51. Amasino RM, Michaels SD: The timing of flowering. Plant Physiol 2010, 154:516-520 http://dx.doi.org/10.1104/pp.110.161653.

52. Liu F, Marquardt S, Lister C, Swiezewski S, Dean C: Targeted 3 processing of antisense transcripts triggers Arabidopsis FLC chromatin silencing. Science 2009, 327:94-97 http://dx.doi.org/ 10.1126/science.1180278.

53. Davidovich C, Wang X, Cifuentes-Rojas C, Goodrich KJ,

- Gooding AR, Lee JT, Cech TR: Toward a consensus on the binding specificity and promiscuity of PRC2 for RNA. Mol Cell 2015, 57:552-558 http://dx.doi.org/10.1016/j.molcel.2014.12.017.

This study revisits the issue of the specificity of RNA binding by PRC2. The authors demonstrate that promiscuous and specific RNA-binding activities of PRC2 are not mutually exclusive, thus bridging the two existing models of PRC2-RNA interaction.

54. Swiezewski S, Liu F, Magusin A, Dean C: Cold-induced silencing by long antisense transcripts of an Arabidopsis Polycomb target. Nature 2009, 462:799-802 http://dx.doi.org/10.1038/ nature08618.

55. Helliwell CA, Robertson M, Finnegan EJ, Buzas DM, Dennis ES: Vernalization-repression of Arabidopsis FLC requires promoter sequences but not antisense transcripts. PLOS ONE 2011, 6:e21513 http://dx.doi.org/10.1371/journal.pone.0021513.

56. Csorba T, Questa JI, Sun Q, Dean C: Antisense COOLAIR mediates the coordinated switching of chromatin states at FLC during vernalization. Proc Natl Acad Sci U S A 2014 111:16160-16165 http://dx.doi.org/10.1073/pnas.1419030111.

57. Liu F, Marquardt S, Lister C, Swiezewski S, Dean C: Targeted 3 processing of antisense transcripts triggers Arabidopsis FLC chromatin silencing. Science 2010, 327:94-97 http://dx.doi.org/ 10.1126/science.1180278.

58. Hornyik C, Terzi LC, Simpson GG: The Spen family protein FPA controls alternative cleavage and polyadenylation of RNA. Dev Cell 2010, 18:203-213 http://dx.doi.org/10.1016/ j.devcel.2009.12.009.

59. Marquardt S, Raitskin O, Wu Z, Liu F, Sun Q, Dean C: Functional consequences of splicing of the antisense transcript COOLAIR on FLC transcription. Mol Cell 2014, 54:156-165 http://dx.doi.org/10.1016/j.molcel.2014.03.026.

60. Liu F, Quesada V, Crevillen P, Bäurle I, Swiezewski S, Dean C: The Arabidopsis RNA-binding protein FCA requires a lysinespecific demethylase 1 homolog to downregulate FLC. $\mathrm{Mol}$ Cell 2007, 28:398-407 http://dx.doi.org/10.1016/ j.molcel.2007.10.018.

61. Callahan KP, Butler JS: Evidence for core exosome independent function of the nuclear exoribonuclease Rrp6p. Nucleic Acids Res 2008, 36:6645-6655 http://dx.doi.org/10.1093/nar/gkn743.

62. Kiss DL, Andrulis ED: Genome-wide analysis reveals distinct substrate specificities of Rrp6, Dis3, and core exosome subunits. RNA 2010, 16:781-791 http://dx.doi.org/10.1261/ rna.1906710.

63. Fox MJ, Gao H, Smith-Kinnaman WR, Liu Y, Mosley AL: The -• exosome component Rrp6 is required for RNA polymerase II termination at specific targets of the Nrd1-Nab3 pathway. PLoS Genet 2015, 10:e1004999 http://dx.doi.org/10.1371/ journal.pgen.1004999.
This study demonstrates that Rrp6 activity is required for efficient Pol II transcription termination in non-canonical $3^{\prime}$-end processing pathway in yeast.

64. Ciaudo C, Bourdet A, Cohen-Tannoudji M, Dietz HC, Rougeulle C Avner P: Nuclear mRNA degradation pathway(s) are implicated in Xist regulation and $X$ chromosome inactivation. PLOS Genet 2006, 2:e94 http://dx.doi.org/10.1371/journal.pgen.0020094.

65. Sun Q, Csorba T, Skourti-Stathaki K, Proudfoot NJ, Dean C: Rloop stabilization represses antisense transcription at the Arabidopsis FLC locus. Science 2013, 340:619-621 http:// dx.doi.org/10.1126/science.1232808.

66. Skourti-Stathaki K, Kamieniarz-Gdula K, Proudfoot NJ: R-loops induce repressive chromatin marks over mammalian gene terminators. Nature 2014, 516:436-439 http://dx.doi.org/ 10.1038/nature13787

67. Hacisuleyman E, Goff LA, Trapnell C, Williams A, Henao-Mejia J,

- Sun L, McClanahan P, Hendrickson DG, Sauvageau M, Kelley DR Morse M, Engreitz J, Lander ES, Guttman M, Lodish HF, Flavell R, Raj A, Rinn JL: Topological organization of multichromosomal regions by the long intergenic noncoding RNA firre. Nat Struct Mol Biol 2014, 21:198-206 http://dx.doi.org/10.1038/nsmb.2764. This study reports that the Firre IncRNA can modulate inter-chromosomal nuclear architecture.

68. Engreitz JM, Pandya-Jones A, McDonel P, Shishkin A, Sirokman K, Surka C, Kadri S, Xing J, Goren A, Lander ES, Plath K, Guttman M: The Xist IncRNA exploits three-dimensional genome architecture to spread across the $X$ chromosome Science 2013, 341:1237973 http://dx.doi.org/10.1126/ science. 1237973 .

69. Quinodoz S, Guttman M: Long noncoding RNAs: an emerging link between gene regulation and nuclear organization. Trends Cell Biol 2014, 24:651-663 http://dx.doi.org/10.1016/ j.tcb.2014.08.009.

70. Moissiard G, Cokus SJ, Cary J, Feng S, Billi AC, Stroud H, Husmann D, Zhan Y, Lajoie BR, McCord RP, Hale CJ, Feng W, Michaels SD, Frand AR, Pellegrini M, Dekker J, Kim JK, Jacobsen SE: MORC family ATPases required for heterochromatin condensation and gene silencing. Science 2012, 336:1448-1451 http://dx.doi.org/10.1126/science.1221472.

71. Crevillen $\mathrm{P}$, Sonmez C, Wu Z, Dean C: A gene loop containing the floral repressor FLC is disrupted in the early phase of vernalization. EMBO J 2013, 32:140-148 http://dx.doi.org/ 10.1038/emboj.2012.324.

72. Jégu $T$, Latrasse $D$, Delarue $M$, Hirt $H$, Domenichini $S$, Ariel $F$, Crespi M, Bergounioux C, Raynaud C, Benhamed M: The BAF60 subunit of the SWI/SNF chromatin-remodeling complex directly controls the formation of a gene loop at FLOWERING LOCUS C in Arabidopsis. Plant Cell 2014, 26:538-551 http:// dx.doi.org/10.1105/tpc.113.114454.

73. Rosa S, De Lucia F, Mylne JS, Zhu D, Ohmido N, Pendle A, Kato N Shaw P, Dean C: Physical clustering of FLC alleles during polycomb-mediated epigenetic silencing in vernalization. Genes Dev 2013, 27:1845-1850 http://dx.doi.org/10.1101/ gad.221713.113.

74. Law JA, Du J, Hale CJ, Feng S, Krajewski K, Palanca AMS, Strahl BD, Patel DJ, Jacobsen SE: Polymerase IV occupancy at RNA-directed DNA methylation sites requires SHH1. Nature 2013, 498:385-389 http://dx.doi.org/10.1038/nature12178.

75. Liu Z-W, Shao C-R, Zhang C-J, Zhou J-X, Zhang S-W, Li L, Chen S, Huang $\mathrm{H}-\mathrm{W}$, Cai T, He X-J: The SET domain proteins SUVH2 and SUVH9 are required for Pol v occupancy at RNA-directed DNA methylation loci. PLoS Genet 2014, 10:e1003948 http:// dx.doi.org/10.1371/journal.pgen.1003948.

76. Zhu Y, Rowley MJ, Böhmdorfer G, Wierzbicki AT: A SWI/SNF chromatin-remodeling complex acts in noncoding RNAmediated transcriptional silencing. Mol Cell 2013, 49:298-309 http://dx.doi.org/10.1016/j.molcel.2012.11.011. 